\title{
Effect of IFN- $\alpha$ and other commonly used nebulization drugs in different nebulization methods on the resistance of breathing circuit filters under invasive mechanical ventilation
}

\author{
Zhenjie Jiang $^{1 \# \wedge}$, Hanwen Liang ${ }^{2 \#}$, Guixia Peng ${ }^{3 \#}$, Shiya Wang ${ }^{1}$, Baozhu Zhang ${ }^{1}$, Qingwen Sun ${ }^{1}$, \\ Yuanda $\mathrm{Xu}^{1} \wedge$, Huiqing Zeng ${ }^{4}$, Jingye Huang ${ }^{1}$ \\ ${ }^{1}$ Department of Critical Care Medicine, the First Affiliated Hospital of Guangzhou Medical University, Guangzhou, China; ${ }^{2}$ Guangzhou Respiratory \\ Health Research Institute, the First Affiliated Hospital of Guangzhou Medical University, Guangzhou, China; ${ }^{3}$ Department of Pulmonary and \\ Critical Care Medicine, Meizhou People's Hospital, Meizhou, China; ${ }^{4}$ Department of Pulmonary and Critical Care Medicine, Zhongshan Hospital \\ Xiamen University, Xiamen, China \\ Contributions: (I) Conception and design: Y Xu, H Zeng, Z Jiang; (II) Administrative support: None; (III) Provision of study materials or patients: \\ Y Xu, H Zeng, J Huang, G Peng; (IV) Collection and assembly of data: Z Jiang, H Liang, S Wang, B Zhang, Q Sun; (V) Data analysis and \\ interpretation: Z Jiang, H Liang, J Huang, G Peng; (VI) Manuscript writing: All authors; (VII) Final approval of manuscript: All authors. \\ \#These authors contributed equally to this work. \\ Correspondence to: Yuanda Xu. Department of Critical Care Medicine, the First Affiliated Hospital of Guangzhou Medical University, Guangzhou, \\ China. Email: xuyuanda@sina.com; Huiqing Zeng. Department of Pulmonary and Critical Care Medicine, Zhongshan Hospital Xiamen University, \\ Xiamen, China. Email: 13606080893@139.com; Jingye Huang. Department of Critical Care Medicine, the First Affiliated Hospital of Guangzhou \\ Medical University, Guangzhou, China. Email: 463112412@qq.com.
}

Background: Interferon (IFN) is widely used in clinical practice and nebulization inhalation is one of the commonly used routes of administration. However, nebulization drugs such as interferon- $\alpha$ (IFN- $\alpha$ ) with large molecular weights may deposit in the membrane of the breathing filters, causing its resistance to gradually increase. Thus, our study explores the effect of IFN- $\alpha$ and other nebulization drugs on the resistance of breathing circuit filters under invasive mechanical ventilation.

Methods: We divided 96 breathing filters into eight groups. The baseline group was not treated while the blank group was installed but were not nebulized. The remaining groups received jet nebulized or vibrating nebulized with either normal saline, Combivent, Amphotericin B, or IFN- $\alpha$ at a frequency of once every 12 hours separately and were removed from the breathing circuit after 24 hours. The resistance of the filter of each group was then measured and statistical comparisons were made.

Results: Filter resistance of the IFN- $\alpha$ jet nebulization group was greater than that of the other groups, and there were statistical differences except for the Amphotericin B jet nebulization group. Comparison of the resistance $\left[\mathrm{cmH}_{2} \mathrm{O} /(\mathrm{L} \cdot \mathrm{s})\right]$ of the IFN- $\alpha$ jet nebulization group $v s$. the baseline group showed $2.56(2.40,2.68)$ vs. 2.26 (2.03, 2.40), $\mathrm{P}=0.037$; of the IFN- $\alpha$ jet nebulization group $v s$. the blank group showed $2.56(2.40,2.68)$ vs. 2.11 (1.98, 2.27), $\mathrm{P}=0.003$; of the IFN- $\alpha$ jet nebulization group vs. the normal saline group: 2.56 (2.40, 2.68) vs. 2.16 (2.08, 2.32), $\mathrm{P}=0.023$; of the $\mathrm{IFN}-\alpha$ jet nebulization group vs. the Combivent jet nebulization group: 2.56 (2.40, 2.68) vs. 2.18 (2.14, 2.27), $\mathrm{P}=0.018$; and of the IFN- $\alpha$ jet nebulization group vs. the Amphotericin B jet nebulization group: $2.56(2.40,2.68) v s .2 .33(2.05,2.45), \mathrm{P}=0.221$. The effect of jet nebulization and vibrating mesh nebulization on the resistance of breathing filters showed no significant statistical difference.

Conclusions: Jet nebulization with IFN- $\alpha$ significantly increased the resistance of the breathing filter within 24 hours and there was no significant difference in filter resistance between jet nebulization and vibrating mesh nebulization of IFN- $\alpha$ or Amphotericin B.

^ ORCID: Zhenjie Jiang, 0000-0002-0389-0286; Hanwen Liang, 0000-0002-2483-3213; Yuanda Xu, 0000-0002-7843-8876. 
Keywords: Breathing circuit filters; jet nebulization; vibrating mesh nebulization; interferon- $\alpha$ (IFN- $\alpha$ )

Submitted Dec 10, 2021. Accepted for publication Feb 21, 2022.

doi: 10.21037/atm-22-84

View this article at: https://dx.doi.org/10.21037/atm-22-84

\section{Introduction}

Interferon (IFN) is a critical cytokine in human innate immunity and has a broad-spectrum antiviral effect. It is widely used in clinical practice, and nebulization inhalation is one of the commonly used routes of administration. There is in vitro study have shown that severe acute respiratory syndrome coronavirus 2 (SARS-CoV-2) is significantly sensitive to interferon- $\alpha$ (IFN- $\alpha)(1)$, and after nebulization inhalation for 12 hours, the interferon concentration in lung tissue can reach more than four times that of intramuscular injection (2). Therefore, nebulization inhalation may be an ideal route of administration for the application of IFN to treat coronavirus disease 2019 (COVID-19). At present, commonly used nebulization methods include the jet nebulization method and the vibrating mesh nebulization method.

Breathing circuit filters are air filtering devices used in the ventilator circuit, which can help maintain stability of the gas temperature and humidity in the breathing circuit $(3,4)$ and effectively filter out pathogenic microorganisms, avoiding the formation of aerosols which cause cross-infection (5-7). At the same time, breathing filters can also prevent drug particles entering the exhalation valve during the nebulization process to form crystallization causing the exhalation valve to leak, ensuring the synchronization of the man-machine and prolonging the service life of the ventilator.

In the process of using the filters, water vapour accumulates in the breathing circuit (8) and dust, respiratory secretions, and pathogenic microorganisms can gather on the filter membrane, causing the filters' performance of filtering bacteria to gradually decline (9). However, there is no uniform standard for the timing of replacement of the filters. Patients receiving mechanical ventilation often receive nebulization inhalation therapy, and the impact of resistance of the breathing filters on their respiratory mechanics needs to be considered. While nebulization drugs such as IFN- $\alpha$ and Amphotericin B have relatively large molecular weights that easily filter and deposit, there is still a lack of relevant research on their impact on the resistance of the filters.

This study explored the effects of different nebulization drugs such as normal saline, Combivent, Amphotericin
$\mathrm{B}$, and IFN- $\alpha$ on the resistance of breathing circuit filters in vitro simulated breathing circuits and examined the effect of different nebulization methods on the resistance of breathing circuit filters. The results may provide a reference for the timing of breathing filter replacement after nebulization in clinical work. We present the following article in accordance with the MDAR reporting checklist (available at https://atm.amegroups.com/article/ view/10.21037/atm-22-84/rc).

\section{Methods}

The following experimental materials were used: Breathing circuit filters and an Airvo2 Nasal High Flow System (provided by Fisher \& Paykel Healthcare Limited, Auckland, New Zealand); Dräger SelfTestLung, Dräger XL ventilator and its supporting silicone pipeline (provided by Dräger Medical Equipment Co., Ltd., Frankfurt, Germany); LabChart physiological data analysis software; PowerLab16/35 data acquisition device and Signal Conditioners (provided by At ADInstruments International Trading Co., Ltd., New South Wales, Australia); Pressure Sensor DP15-34-N1-S-4-A and Pressure amplifier CD280-4C (provided by Validyne Engineering Co., Ltd., Los Angeles, the US); Flow Sensors MLT 300L (provided by HANS RUDOLPH Co., Ltd., Boston, the US); Aerogen Solo vibrating mesh nebulizers (provided by Aerogen Co., Ltd., Galway, the UK); Recombinant human interferon $\alpha 2 \mathrm{~b}$ injection (provided by Beijing Kawin Technology Share-Holding Co., Ltd., Beijing, China); and Amphotericin B for Injection (provided by North China Pharmaceutical Co., Ltd., Shijiazhuang, China).

\section{Experimental process}

Inclusion criteria: (I) the quality of the filter meets the standard of use; (II) the filters package is in good condition with no obvious damage; (III) the filter is within its expiration date. Exclusion criteria: (I) the breathing filters were used in the breathing circuit for less than or more than 24 hours due to various reasons; (II) the filter is fouled due to human causes during installation or use; (III) due to 


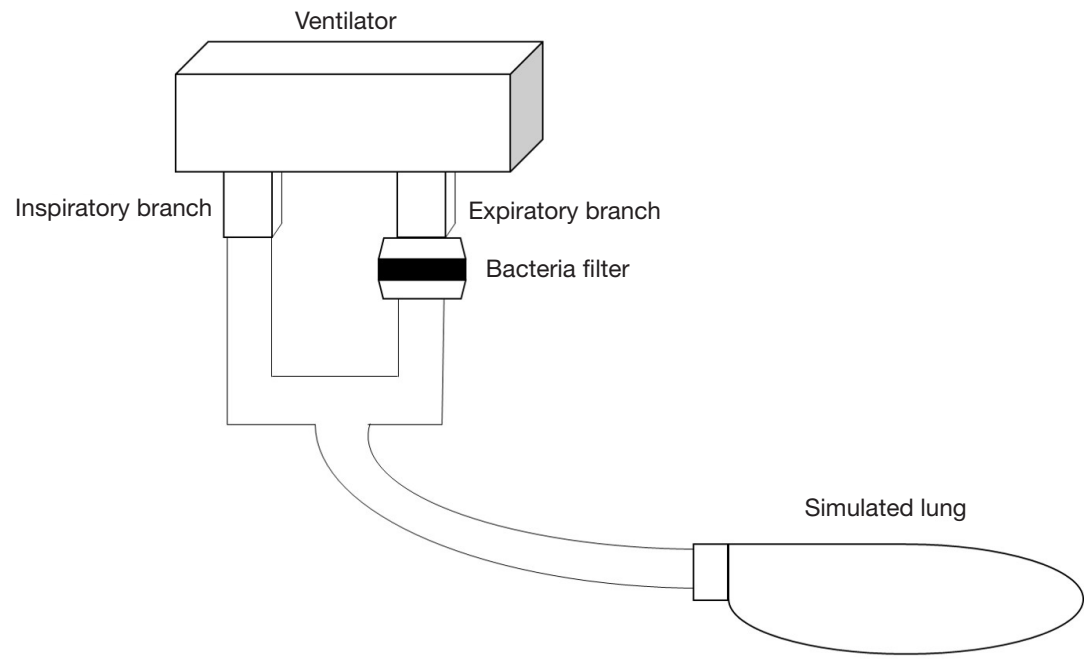

Figure 1 Schematic diagram of the filter placed in the simulated breathing circuit.

various reasons, the nebulization frequency and time did not meet the experimental requirements.

We divided 96 breathing filters into eight groups randomly (the filters are from the same manufacturer and the same batch number, and there is no difference between the filters): baseline group, blank group, normal saline group, Combivent jet nebulization group, Amphotericin B jet nebulization group, Amphotericin B vibrating mesh nebulization group, IFN- $\alpha$ jet nebulization group, and IFN- $\alpha$ vibrating mesh nebulization group. Each group used independent breathing filters to perform the experiment.

Baseline group: the breathing filters of this group did not undergo experimental processing, and their resistance was directly measured.

Filters used by the remaining groups were installed in an in vitro simulated breathing circuit composed of a ventilator and simulated lung (Figure 1) and were processed as follows.

Blank group: the filters of this group were not treated with nebulization and were removed from the breathing circuit after 24 hours; normal saline group: the filters of this group were jet nebulized with $5 \mathrm{~mL}$ normal saline at a frequency of once every 12 hours and removed from the breathing circuit after 24 hours; Combivent jet nebulization group: The filters of this group were jet nebulized with $2.5 \mathrm{~mL}$ normal saline and $2.5 \mathrm{~mL}$ Combivent at a frequency of once every 12 hours and removed from the breathing circuit after 24 hours; Amphotericin B jet nebulization group/ Amphotericin B vibrating mesh nebulization group: $5 \mathrm{mg}$ Amphotericin B was dissolved in $5 \mathrm{~mL}$ normal saline and the two groups of filters were treated with jet nebulization/ vibrating mesh nebulization separately with these medicines. Both groups were removed from the breathing circuit after 24 hours; IFN- $\alpha$ jet nebulization group/IFN- $\alpha$ vibrating mesh nebulization group: in the two groups, we mixed $0.3 \mathrm{~mL}$ ( 3 million IU) of recombinant human interferon $\alpha 2 \mathrm{~b}$ injection and normal saline into a $5 \mathrm{~mL}$ solution and treated the two groups of filters with jet nebulization/ vibrating mesh nebulization separately before removing them from the breathing circuit after 24 hours.

\section{Measurement process}

After the pressure sensor and flow sensor were calibrated and zeroed, the gas flow rate regulator, pressure sensor, flow sensor, and breathing filter were connected and tested (Figure 2).

The gas flow rate was set to $40 \mathrm{~L} / \mathrm{min}$ and the temperature to $34^{\circ} \mathrm{C}$. After the gas flow rate was stabilized, the LabChart physiological data analysis software collected and recorded the pre-filtered air pressure (P1), the postfiltered air pressure (P2), and the gas flow (Q) per unit time in real-time to obtain the average value of the data mentioned above. According to Poiseuille's Law: $Q=\frac{\pi 4^{4} \Delta P}{8 \eta L}$, $R=\frac{8 \eta L}{\pi r^{4}}, Q=\frac{\Delta P}{R}, R=\frac{\Delta P}{Q}=\frac{P_{1}-P_{2}}{Q}$, substituting the above $\mathrm{P} 1, \mathrm{P} 2$, and $\mathrm{Q}$ into the above formula, the breathing filter resistance was determined as $\mathrm{R}$.

\section{Statistical analysis}

All statistical analyses were performed using R software 


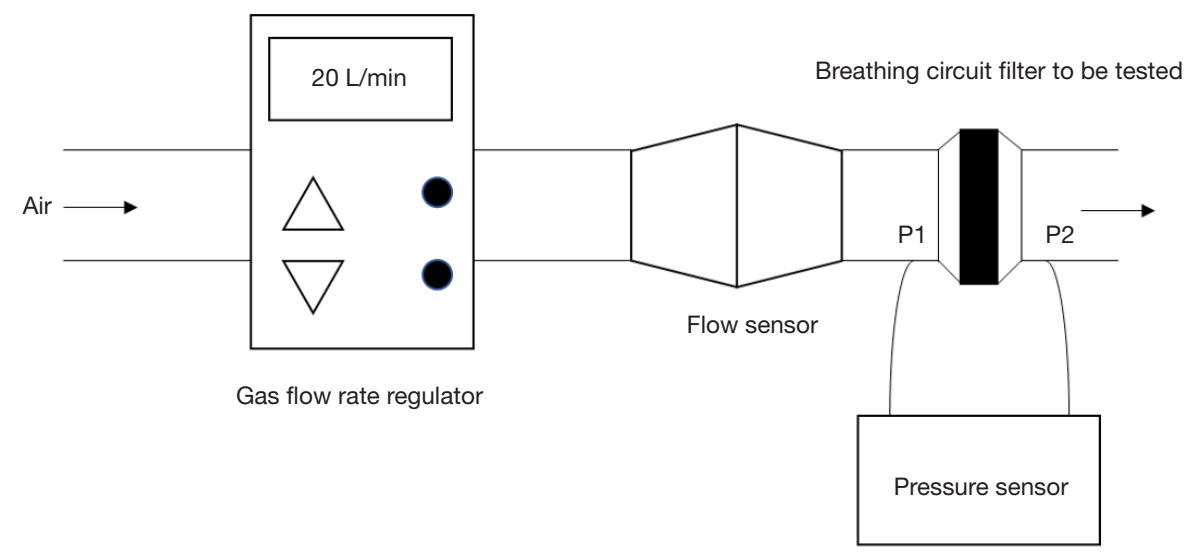

Figure 2 Breathing circuit filter resistance measurement schematic.

Table 1 Effect of different nebulization drugs on the resistance of breathing circuit filters

\begin{tabular}{ll}
\hline Group & $\mathrm{R}\left[\mathrm{cmH}_{2} \mathrm{O} /(\mathrm{L} \cdot \mathrm{s})\right]$ \\
\hline Baseline group & $2.26(2.03,2.40)$ \\
Blank group & $2.11(1.98,2.27)$ \\
Normal saline group & $2.16(2.08,2.32)$ \\
Combivent jet nebulization group & $2.18(2.14,2.27)$ \\
Amphotericin B jet nebulization group & $2.33(2.05,2.45)$ \\
IFN- $\alpha$ jet nebulization group & $2.56(2.40,2.68)$ \\
\hline
\end{tabular}

The data above were expressed as median (interquartile range). IFN, interferon.

(v4.1.1), and given the small sample sizes, we adopted conservative non-parametric tests $(10,11)$. Differences between groups were assessed with Kruskal-Wallis, and continuous variables were presented as medians with interquartile ranges. $\mathrm{P}$ value $<0.05$ was considered statistically significant.

\section{Results}

The filter resistance of the groups was compared in pairs. The results showed that: in terms of the effect of different nebulization drugs on the resistance of breathing circuit filters, the filter resistance of the IFN- $\alpha$ jet nebulization group was greater than that of the other groups, and there were statistical differences except for the Amphotericin B jet nebulization group $(\mathrm{P}<0.05)$ (Tables 1,2, Figure 3).

Regarding the effect of different nebulization methods on the resistance of breathing circuit filters, we compared the filter resistance of the Amphotericin B jet nebulization group with the Amphotericin B vibrating mesh nebulization group and the IFN- $\alpha$ jet nebulization group with the IFN- $\alpha$ vibrating mesh nebulization group. The results showed that within 24 hours of use, there was no significant statistical difference in the impact of the above two drugs on the resistance of the breathing filters under the two different nebulization methods (Table 3, Figures 4,5).

\section{Discussion}

COVID-19 caused by SARS-CoV-2 has swept the world. As of November 17, 2021, there were more than 250 million confirmed cases worldwide and more than 5.11 million deaths (12). There are currently no targeted antiviral drugs for COVID-19 validated through rigorous trials, and only some show specific treatment effects in clinical observation and research. In the "Chinese recommendations for diagnosis and treatment of novel coronavirus SARS-CoV2 infection (Trial 8th version)", it is recommended that adult patients try nebulization inhalation treatment of 5 million IU or an equivalent dose of interferon at the frequency of twice a day, and the course of treatment should not exceed 10 days (13).

In the context of the widespread epidemic of COVID-19, breathing filters are widely used in clinical practice due to their advantages in reducing respiratory circuit pollution and avoiding nosocomial infections. However, a study has shown that the performance indicators of filters gradually change during use, including resistance (9). For critically ill patients with COVID-19 who require invasive ventilation, the increase in the resistance of the breathing filters is more likely to cause an increase in the patient's labour of 
Table 2 Comparison of $\mathrm{P}$ value between different groups

\begin{tabular}{|c|c|c|c|c|c|}
\hline Groups & \multicolumn{5}{|c|}{$P$ values } \\
\hline \multicolumn{6}{|l|}{ Baseline group } \\
\hline Blank group & 0.993 & & & & \\
\hline Amphotericin B jet nebulization group & 0.995 & 0.787 & 0.984 & 0.976 & \\
\hline IFN- $\alpha$ jet nebulization group & 0.037 & 0.003 & 0.023 & 0.018 & 0.221 \\
\hline
\end{tabular}

IFN, interferon.

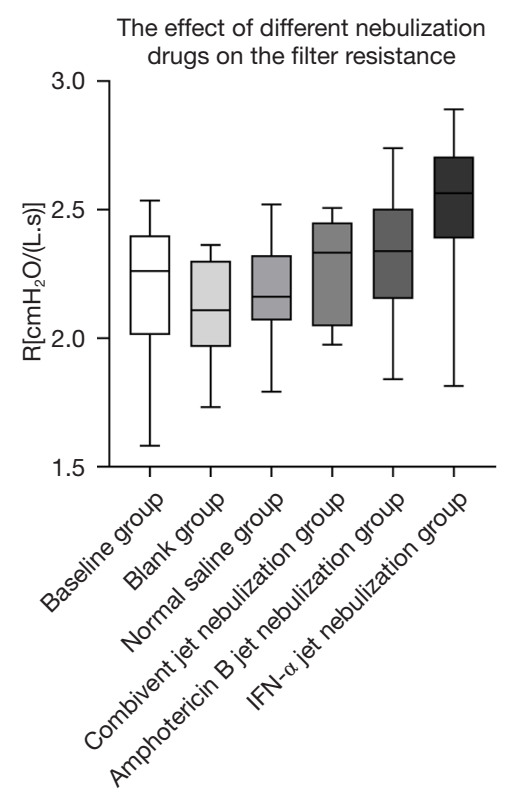

Figure 3 The effect of different nebulization drugs on the filter resistance.

Table 3 Different nebulization methods on the resistance of breathing circuit filters

\begin{tabular}{|c|c|c|}
\hline Group & $\mathrm{R}\left[\mathrm{cmH}_{2} \mathrm{O} /(\mathrm{L} \cdot \mathrm{s})\right]$ & $\mathrm{P}$ \\
\hline Amphotericin B jet nebulization group & $2.33(2.05,2.45)$ & 0.999 \\
\hline $\begin{array}{l}\text { Amphotericin B vibrating mesh } \\
\text { nebulization group }\end{array}$ & $2.34(2.18,2.49)$ & \\
\hline IFN- $\alpha$ jet nebulization group & $2.56(2.40,2.68)$ & 0.928 \\
\hline IFN- $\alpha$ vibrating mesh nebulization group & $2.32(2.29,2.54)$ & \\
\hline
\end{tabular}

The data above were expressed as median (interquartile range).

IFN, interferon.

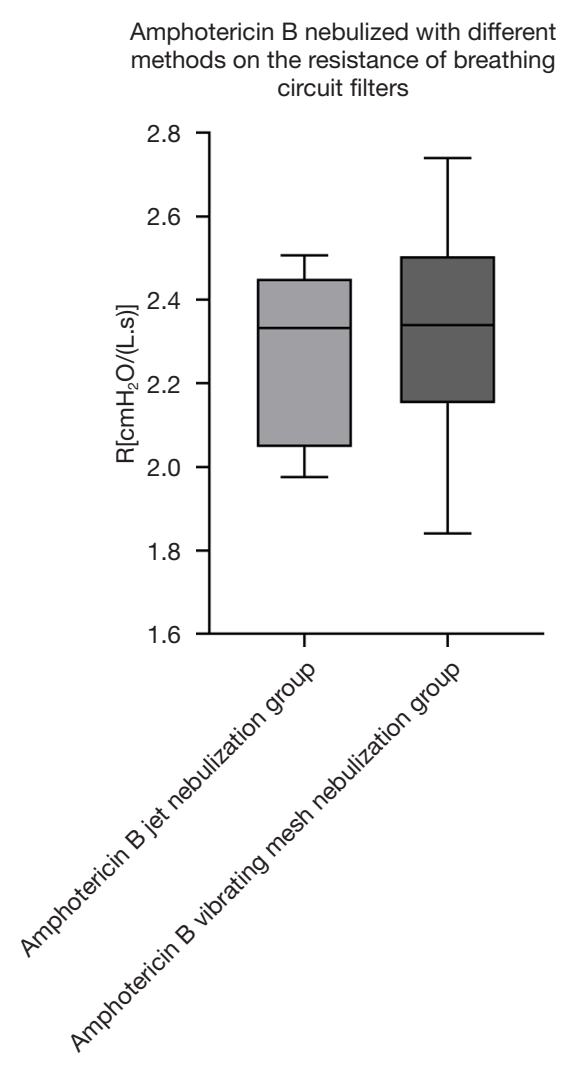

Figure 4 Amphotericin B nebulized with different methods on the resistance of breathing circuit filters. 


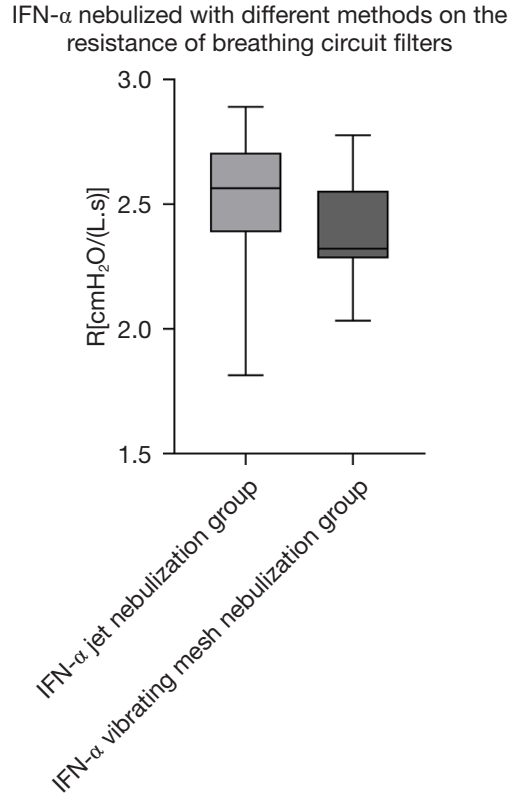

Figure 5 Interferon- $\alpha$ nebulized with different methods on the resistance of breathing circuit filters.

breathing, leading to human-machine asynchrony (14) and aggravating breathing difficulties. However, replacing the filters too frequently not only increases labour and medical costs but as the respiratory circuit is connected to the outside world during the replacement process, the risk of infectious aerosol spread increases (15). Currently, there is no consensus on the replacement time of breathing filters-Branson (16) recommended replacement after one week while Boyer et al. (17) recommended replacement after $48 \mathrm{~h}$. There are many factors that may affect breathing filter resistance, including the type and concentration of nebulization drugs, different modes and parameter settings of the ventilator, nebulization equipment and the patient's own disease conditions. Breathing filters mainly play a filtering role through direct interception (particle size $>1 \mu \mathrm{m}$ ), inertial impact (particle size $0.5-1 \mu \mathrm{m}$ ), and diffusion interception (particle size $<0.5 \mu \mathrm{m})(18)$. Therefore, the size and mass of the aerosol particles in the breathing circuit will affect the resistance of the filter. The size and weight of the nebulization aerosol may be affected by the type of the drug itself, the relative molecular weight, nebulization equipment and even the solvent of the drugs (19). The nebulization aerosol with a large particle size and molecular weight is easy to be directly intercepted and easier to deviate from the direction of the airflow and hit the fiber of the membrane, resulting in an increase in filter resistance. When the drug concentration is high, more molecules pass through the filter membrane per unit time, and more nebulization drug molecules are deposited on the filter membrane, and the resistance of the respiratory filter may increase more significantly within the same use time. Similarly, some specific parameters and modes of the ventilator may also affect the resistance of the filter. For example, when the gas flow rate in the breathing circuit is fast, the gas is more likely to form turbulent flow when passing through the filter, and lead to an increase in resistance as well. At the same time, the humidified gas in the ventilator circuit may also have an effect on the resistance of the filter-the humidified airflow in the respiratory circuit makes water accumulate in the filter membrane. A study has shown that the resistance of the breathing filters can be increased by $70 \%$ to $480 \%$ after the breathing filter absorbs water (20). Finally, for patients with massive or thick respiratory secretions, the application of breathing filters should also be cautious (21) - these secretions have the risk of blocking the filters and causing a sharp increase in resistance.

The factors mentioned above are closely related to the type of the disease because the airway resistance is further increased due to the increase of breathing filter resistance. In patients with acute respiratory distress syndrome (ARDS), the airflow rate of the ventilator is often faster, and the increase of the resistance of the breathing filter at this time may cause the increase in intrinsic positive end expiratory pressure (PEEPi), aggravating lung damage (22). At the same time, it may also affect the flow triggering of the ventilator, increasing the risk of human-machine asynchrony. For patients with airway obstruction diseases such as bronchial asthma and chronic obstructive pulmonary disease (COPD), the increase in filter resistance may lead to increased inspiratory work $(23,24)$ and insufficient inspiratory process, resulting in delayed ventilator delivery. Therefore, the timing of filter replacement is worthy of discussion.

The results of our study showed that the filter resistance of the IFN- $\alpha$ jet nebulization group was greater than that of all other groups in the $24 \mathrm{~h}$ use time, and the differences between the IFN- $\alpha$ jet nebulization and the baseline, blank, normal saline, and Combivent jet nebulization groups were statistically significant. At the same time, although there was no statistical difference in the filter resistance of the Amphotericin B jet nebulization group compared with other groups, the median of filter resistance of this group was still greater than that of all groups except the IFN- $\alpha$ group, suggesting an increase in the experimental sample 


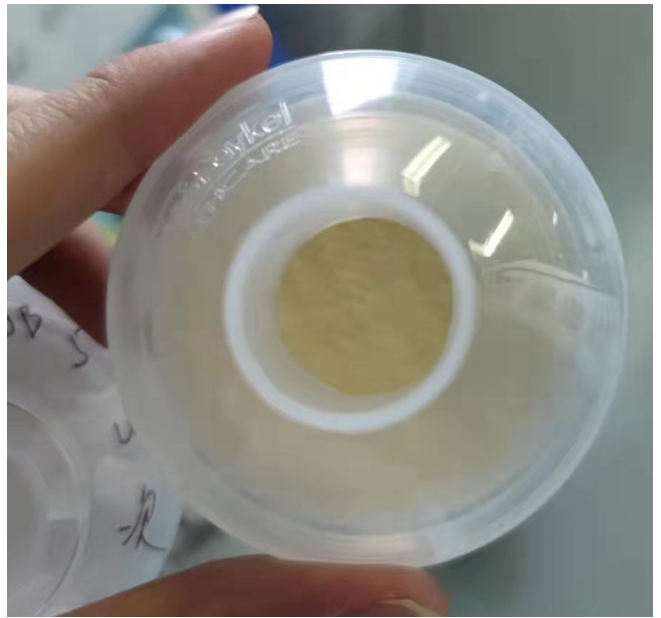

Figure 6 The filter membrane is stained yellow after Amphotericin B nebulization.

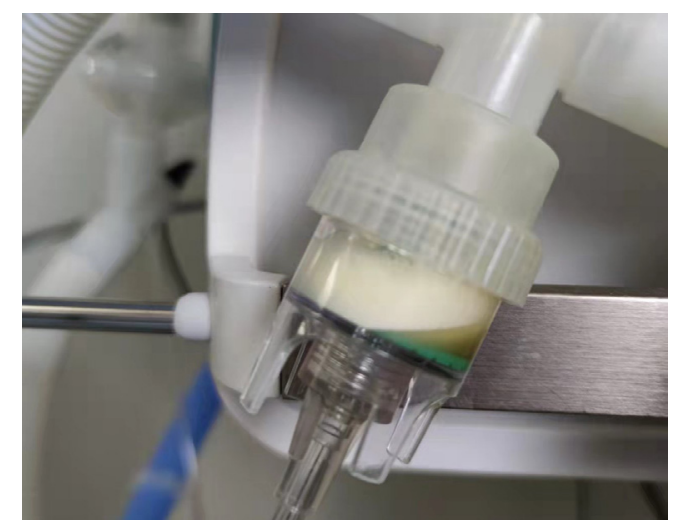

Figure 7 Liquid medicine remains in the jet nebulizer.

size may render the difference statistically significant. The reason for the above phenomenon may be that compared with normal saline, which has a relative molecular mass: of 58.4, Ipratropium bromide and salbutamol, which are the main ingredients of Combivent, have relative molecular masses of 412.3 and 239.3, respectively). In addition, the relative molecular masses of Amphotericin B and IFN$\alpha 2 \mathrm{~b}$ are significantly larger [the former is 924.08 , and the latter can reach 65,000 (25)]. The above differences may lead to differences in particle size and weight of the aerosols formed by their nebulization. When the drug-aerosol with larger size and higher weight flows through the filter it is filtered out and deposited on the filter membrane easier and gradually blocks the sieve holes, thereby increasing the resistance of the filter, which is consistent with clinical observations. Taking the coloured drug Amphotericin B as an example, we often see apparent yellow staining of the filter membrane with the naked eye after nebulization treatment (Figure 6). Therefore, we suggest that intubation patients should have their breathing filters promptly replaced after nebulization treatment with Amphotericin B, IFN- $\alpha$, and other macromolecular drugs.

At the same time, the results of our study also showed that for Amphotericin B and IFN- $\alpha 2 b$, jet nebulization and vibrating mesh nebulization had no significant difference on breathing filter resistance. Jet nebulization is currently the most used nebulization method, and uses high-speed airflow to impact the liquid and form a negative pressure around it, which entrains the liquid into the airflow forming aerosols (26). However, the aerosol particles produced by jet nebulization are of different sizes, and part of the liquid medicine remains in the equipment (Figure 7), which reduces nebulization efficiency. A study shows that in the process of jet nebulization, the activity of IFN- $\alpha$ may be reduced due to the formation of insoluble non-covalent polymers because of mechanical damage (27). The method of vibrating mesh nebulization uses electricity to vibrate the liquid through small sieves to form aerosols (28). Therefore, the aerosol particles created are smaller and uniform in size (29) allowing the nebulizer to deliver more inhaled medication to the lungs, in less time, with less residual volume $(30,31)$. In terms of the effect of nebulized inhalation on respiratory mechanics indicators during mechanical ventilation, compared with jet nebulization, vibrating mesh nebulization also has certain advantages. Driven by additional airflow, jet nebulization increases the base airflow. It may affect mechanical indicators such as tidal volume (VT), peak inspiratory pressure (Ppeak), positive end expiratory pressure (PEEP) etc., result in the increase of them (especially in Volume Control Ventilation Mode) and lead to poor triggering, affecting the air supply of the ventilator $(32,33)$. When the resistance of the breathing filter increases due to nebulization treatment, the above effects on respiratory mechanics may be more significant. Vibrating mesh nebulization forms aerosols through vibrate liquid, which will not have a significant impact on the mechanical indicators of respiratory mechanics (28). As the two nebulization methods have similar effects on breathing filter resistance, combined with the above advantages, vibrating mesh nebulization may be a better IFN- $\alpha$ nebulization method.

Nebulization inhalation therapy is one of the important treatment methods for patients receiving mechanical 
ventilation. Ehrmann et al. (34) investigated 854 ICUs from 611 departments in 70 countries around the world and concluded that $99 \%$ of the patients needed mechanical ventilation combined with nebulization inhalation therapy. The type of nebulized drug, whether the choice of nebulization device and method is reasonable (35), the clinical operation in the nebulization process, etc., may all affect the nebulization effect. Therefore, it is necessary to further standardize the operation of nebulization therapy. The results of this study may provide some reference for the timing of breathing filter replacement and the choice of nebulization methods for patients receiving nebulization treatment in clinical practice.

\section{Conclusions}

Compared with other commonly used nebulization drugs, IFN- $\alpha$ nebulization significantly increases the resistance of breathing filters, while Amphotericin B may also affect it. Therefore, breathing filters should be replaced in a timely manner after nebulization treatment with macromolecular drugs. While jet nebulization and vibrating mesh nebulization did not significantly differ in their effect on the resistance of breathing filters, other advantages of vibrating mesh nebulization may render it a better method.

\section{Limitations}

The study still has some limitations: first, it is an in vitro simulation experiment with relatively short observation and during the experiment, the gas flow rate in the breathing circuit is basically constant. In a practical situation, the factors that affect the resistance of breathing filter are much more complex, including the patient's conditions mentioned above such as the massive and thick secretions, the specific mode parameters of the ventilator, or even the degree of standardization of the clinician' operation. Thus, a longer in vivo experimental observation is required. Secondly, although the results of the study clarified that IFN- $\alpha 2 b$ significantly increases the resistance of the breathing filter, whether the degree of change of the filter resistance is sufficient to cause significant changes in respiratory mechanics indicators including airway resistance, airway peak pressure, and the work of breathing, requires further study.

\section{Acknowledgments}

Funding: This study was supported by Zhongnanshan
Medical Foundation of Guangdong Province (No. ZNSA2020001) and Independent Project of State Key Laboratory of respiratory diseases (SKLRD2016ZJ007/008).

\section{Footnote}

Reporting Checklist: The authors have completed the MDAR reporting checklist. Available at https://atm.amegroups. com/article/view/10.21037/atm-22-84/rc

Data Sharing Statement: Available at https://atm.amegroups. com/article/view/10.21037/atm-22-84/dss

Conflicts of Interest: All authors have completed the ICMJE uniform disclosure form (available at https://atm. amegroups.com/article/view/10.21037/atm-22-84/coif). The authors have no conflicts of interest to declare.

Ethical Statement: The authors are accountable for all aspects of the work in ensuring that questions related to the accuracy or integrity of any part of the work are appropriately investigated and resolved.

Open Access Statement: This is an Open Access article distributed in accordance with the Creative Commons Attribution-NonCommercial-NoDerivs 4.0 International License (CC BY-NC-ND 4.0), which permits the noncommercial replication and distribution of the article with the strict proviso that no changes or edits are made and the original work is properly cited (including links to both the formal publication through the relevant DOI and the license). See: https://creativecommons.org/licenses/by-nc-nd/4.0/.

\section{References}

1. Mantlo E, Bukreyeva N, Maruyama J, et al. Antiviral activities of type I interferons to SARS-CoV-2 infection. Antiviral Res 2020;179:104811.

2. Momattin H, Mohammed K, Zumla A, et al. Therapeutic options for Middle East respiratory syndrome coronavirus (MERS-CoV)--possible lessons from a systematic review of SARS-CoV therapy. Int J Infect Dis 2013;17:e792-8.

3. Chiumello D, Pelosi P, Park G, et al. In vitro and in vivo evaluation of a new active heat moisture exchanger. Crit Care 2004;8:R281-8.

4. Unal N, Kanhai JK, Buijk SL, et al. A novel method of evaluation of three heat-moisture exchangers in six different ventilator settings. Intensive Care Med 
1998;24:138-46.

5. Vézina DP, Trépanier CA, Lessard MR, et al. Anesthesia breathing circuits protected by the DAR Barrierbac S breathing filter have a low bacterial contamination rate. Can J Anaesth 2001;48:748-54.

6. Kirton OC, DeHaven B, Morgan J, et al. A prospective, randomized comparison of an in-line heat moisture exchange filter and heated wire humidifiers: rates of ventilator-associated early-onset (community-acquired) or late-onset (hospital-acquired) pneumonia and incidence of endotracheal tube occlusion. Chest 1997;112:1055-9.

7. Moerman M, Lawson G, Andry G, et al. The Belgian experience with the cyranose heat moisture exchange filter. A multicentric pilot study of 12 total laryngectomees. Eur Arch Otorhinolaryngol 2003;260:301-3.

8. Scott DH, Fraser S, Willson P, et al. Passage of pathogenic microorganisms through breathing system filters used in anaesthesia and intensive care. Anaesthesia 2010;65:670-3.

9. Hong Y, Yang X. Application of respiratory filter in patients with noninvasive mechanical ventilation. Journal of Chongqing Medical University 2017;42:1196-9.

10. Kaun KR, Azanchi R, Maung Z, et al. A Drosophila model for alcohol reward. Nat Neurosci 2011;14:612-9.

11. Perera T, Tan JL, Cole MH, et al. Balance control systems in Parkinson's disease and the impact of pedunculopontine area stimulation. Brain 2018;141:3009-22.

12. COVID-19 Dashboard by the Center for Systems Science and Engineering (CSSE) at Johns Hopkins University (JHU)EB/OL. Available online: https://coronavirus.jhu. edu/map.html

13. National Health Commission of the People's Republic of China. Chinese recommendations for diagnosis and treatment of novel coronavirus SARSCoV2) infection (Trial 8th version). Chinese Journal of Clinical Infectious Diseases 2020;13:321-8.

14. Zheng Z, Chen R, Wang X, et al. Respiratory response to the progressing expiratory loading and its effect on patient-ventilator synchronization. Chinese Journal of Biomedical Engineering 2008;14:22-26.

15. Dyer ED, Peterson DE. How far do bacteria travel from the exhalation valve of IPPB equipment? Nurs Res Conf 1972;8:155-61.

16. Branson RD. The ventilator circuit and ventilatorassociated pneumonia. Respir Care 2005;50:774-85; discussion 785-7.

17. Boyer A, Thiéry G, Lasry S, et al. Long-term mechanical ventilation with hygroscopic heat and moisture exchangers used for 48 hours: a prospective clinical, hygrometric, and bacteriologic study. Crit Care Med 2003;31:823-9.

18. Hedley RM, Allt-Graham J. Heat and moisture exchangers and breathing filters. Br J Anaesth 1994;73:227-36.

19. Xu P, Ye W, Yuan Q. Determination of particle size of atomized aerosols in different media. China Public Health 2001;17:265.

20. Turnbull D, Fisher PC, Mills GH, et al. Performance of breathing filters under wet conditions: a laboratory evaluation. Br J Anaesth 2005;94:675-82.

21. Iotti GA, Olivei MC, Braschi A. Mechanical effects of heat-moisture exchangers in ventilated patients. Crit Care 1999;3:R77-82.

22. Amato MB, Barbas CS, Medeiros DM, et al. Effect of a protective-ventilation strategy on mortality in the acute respiratory distress syndrome. N Engl J Med 1998;338:347-54.

23. Bell GT, Martin KM, Beaton S. Work of breathing in anesthetized infants increases when a breathing system filter is used. Paediatr Anaesth 2006;16:939-43.

24. Johnson PA, Raper RF, Fisher MM. The impact of heat and moisture exchanging humidifiers on work of breathing. Anaesth Intensive Care 1995;23:697-701.

25. Tang L, Chen X, Cao C, et al. Quality Control Methods for PEG-IFNa2b. China Pharmacist 2010,13:1592-4.

26. Egan DF, Wilkins RL, Stoller JK, et al. Egan's fundamentals of respiratory care. The C.V. Mosby Co., 2013.

27. Wyde PR, Wilson SZ, Kramer MJ, et al. Pulmonary deposition and clearance of aerosolized interferon. Antimicrob Agents Chemother 1984;25:729-34.

28. Dhand R. Nebulizers that use a vibrating mesh or plate with multiple apertures to generate aerosol. Respir Care 2002;47:1406-18.

29. Michotte JB, Jossen E, Roeseler J, et al. In vitro comparison of five nebulizers during noninvasive ventilation: analysis of inhaled and lost doses. J Aerosol Med Pulm Drug Deliv 2014;27:430-40.

30. Dugernier J, Hesse M, Vanbever R, et al. SPECT-CT Comparison of Lung Deposition using a System combining a Vibrating-mesh Nebulizer with a Valved Holding Chamber and a Conventional Jet Nebulizer: a Randomized Cross-over Study. Pharm Res 2017;34:290-300.

31. Hickin S, Mac Loughlin R, Sweeney L, et al. Comparison of mesh nebulizer versus jet nebulizer in simulated adults with chronic obstructive pulmonary disease. Poster Coll Emerg Med Clin Excell Conf; 2014.

32. Ari A, Fink JB, Dhand R. Inhalation therapy in patients receiving mechanical ventilation: an update. J Aerosol Med Pulm Drug Deliv 2012;25:319-32. 
33. Fink J, Ari A. Aerosol delivery to intubated patients. Expert Opin Drug Deliv 2013;10:1077-93.

34. Ehrmann S, Roche-Campo F, Sferrazza Papa GF, et al. Aerosol therapy during mechanical ventilation: an international survey. Intensive Care Med 2013;39:1048-56.

Cite this article as: Jiang Z, Liang $H$, Peng G, Wang S, Zhang B, Sun Q, Xu Y, Zeng H, Huang J. Effect of IFN- $\alpha$ and other commonly used nebulization drugs in different nebulization methods on the resistance of breathing circuit filters under invasive mechanical ventilation. Ann Transl Med 2022;10(4):189. doi: 10.21037/atm-22-84
35. Ari A, Fink JB. Factors affecting bronchodilator delivery in mechanically ventilated adults. Nurs Crit Care 2010;15:192-203.

(English Language Editor: B. Draper) 